\title{
BCR-ABL1-like acute lymphoblastic leukemia in childhood and targeted therapy
}

Haematologica 2020

Volume 105(9):2200-2204

\section{Correspondence: \\ ANDREA BIONDI \\ abiondi.unimib@gmail.com \\ Received: March 7, 2019. \\ Accepted: May 8, 2020. \\ Pre-published: May 15, 2020.}

doi:10.3324/haematol.2018.207019

(C)2020 Ferrata Storti Foundation

Material published in Haematologica is covered by copyright. All rights are reserved to the Ferrata Storti Foundation. Use of published material is allowed under the following terms and conditions:

https://creativecommons.org/licenses/by-nc/4.0/legalcode. Copies of published material are allowed for personal or internal use. Sharing published material for non-commercial purposes is subject to the following conditions: https://creativecommons.org/licenses/by-nc/4.0/legalcode, sect. 3. Reproducing and sharing published material for commercial purposes is not allowed without permission in writing from the publisher.

\section{Gunnar Cario, ${ }^{1 *}$ Veronica Leoni, ${ }^{2 *}$ Valentino Conter, ${ }^{2 *}$ André Baruchel, ${ }^{3 *}$ Martin Schrappe ${ }^{1 \#}$ and Andrea Biondi ${ }^{\# \#}$}

${ }^{1}$ Pediatrics, University Hospital Schleswig-Holstein, Campus Kiel, Kiel, Germany; ${ }^{2} \mathrm{Clinica}$ Pediatrica and Centro Ricerca Tettamanti, Università di Milano-Bicocca, Hospital S.Gerardo, Monza, Italy and ${ }^{3}$ Hôpital Universitaire Robert Debré (APHP) and Université de Paris, Paris, France

*GC, VL and VC contributed equally to this work as co-first authors.

${ }^{*} A B, M S$ and $A B$ contributed equally as co-senior authors.

$\Lambda$ cute lymphoblastic leukemia (ALL) is a constellation of diseases driven by genetic alterations commonly derived from structural chromosome rearrangements, aneuploidy and co-operating mutations in genes that encode for transcription factors regulating lymphoid development, tumor suppressors, proteins regulating cell cycle progression, and epigenetic modifiers. ${ }^{1}$

Recent years have witnessed dramatic progress in ALL classification. Subtypes of ALL can be defined according to the nature of specific sentinel genetic aberrations that confer distinct biological and clinical characteristics. Some of them represent a therapeutic target for specific treatments, which may contribute to a further increase in cure rates, to reduce the intensity of conventional chemotherapy and/or the need for hematopoietic stem cell transplantation (HSCT).

One of the first genetic aberrations identified was the Philadelphia chromosome $(\mathrm{Ph})$, characterized by the $\mathrm{t}(9 ; 22)(\mathrm{q} 34 ; \mathrm{q} 11)$ translocation that produces the $B C R-A B L 1$ gene, and, in turn, a constitutively active tyrosine kinase. $B C R-A B L 1$ fusion is present in $3-5 \%$ of pediatric ALL and in $25 \%$ of adult ALL patients. The evidence of this genetic aberration allowed the introduction of targeted therapy with tyrosine kinase inhibitors (TKI), which has dramatically improved the outcome of this subset of ALL. ${ }^{2-10}$ The pediatric COG AALL1131 and AALL0622 studies, and the contemporary EsPhALL2004 and subsequent EsPhALL2010 trials, in fact, showed a clear advantage in $\mathrm{Ph}$ positive $\left(\mathrm{Ph}^{+}\right)$ALL from early, continuous and protracted exposure to TKI combined with chemotherapy, challenging the indications for HSCT. ${ }^{5.10}$ Of note, however, the combination of chemotherapy and TKI may also be associated with increased toxicity, as shown in the EsPhALL2010 study. ${ }^{6,7}$

With advanced technologies, such as whole genome and transcriptome sequencing, novel genetic subtypes have recently been discovered. In 2009, among the so called "B-other", a subgroup of B-cell precursor (BCP)-ALL lacking the known sentinel BCP-ALL genetic aberrations, a new category of ALL has been described by Mullighan $^{11}$ and by den Boer ${ }^{12}$, and termed Philadelphia chromosome (Ph)-like and $B C R-A B L 1$-like ALL, respectively. The second term is used in this paper. The two signatures are based on the prediction analysis of microarrays (PAM) classifier consisting of 257 gene probe sets trained on $\mathrm{Ph}^{+}$ALL cases $\left(\right.$Mullighan $\left.^{11}\right)$ or on hierarchical clustering of 110 gene probe sets identified to predict the major pediatric ALL subtypes (den Boer), with only nine overlapping probe sets. ${ }^{12} B C R$-ABL1-like ALL, defined by a gene expression profile greatly similar to that of $\mathrm{Ph}^{+} \mathrm{ALL}$, presents a high frequency of deletions of IKZF1, which encodes the lymphoid transcription factor IKAROS, and of other lymphoid transcription factor genes. ${ }^{11,13} B C R$-ABL1-like ALL has been recognized as a provisional entity in the 2016 World Health Organization classification of myeloid neoplasms and acute leukemia; $;^{14}$ the prevalence varies with age from $12 \%$ in children to $21 \%$ in adolescents, $27 \%$ in young adults, and $20-24 \%$ in older adults with BCP-ALL. In addition to older age at diagnosis, BCR-ABL1-like ALL is associated with other high-risk clinical features, such as elevated leukocyte count at diagnosis and poor treatment response, i.e. high levels of end-induction minimal residual disease (MRD), increased risk of induction failure and of relapse. ${ }^{11,13,15-30}$

Importantly, $B C R$ - $A B L 1$-like ALL is not defined by a single unifying sentinel molecular aberration; but rather, it is characterized by a variety of genomic alterations that activate kinases and deregulate cytokine receptor signaling. Fusion genes involving at least 17 cytokine receptors or tyrosine kinases have been identified. $23,29,31,32$ These alterations can be grouped into several major subclasses: approximately $50 \%$ of $B C R$ - 
ABL1-like cases harbor rearrangements of the cytokine receptor like factor 2 (CRLF2) resulting in upregulation of CRLF2 expression, in the vast majority as a consequence of either a translocation resulting in IGH-CRLF2 juxtaposition or a deletion of the PAR region of the $\mathrm{X}$ chromosome leading to the P2RY8-CRLF2 fusion. Frequent concomitant activating gene mutations occur in Janus kinases or other regulators of JAK-STAT signaling, with about $50 \%$ of CRLF2 rearranged cases presenting JAK1 or JAK2 point mutations. ${ }^{15,16,33,34}$ However, although the P2RY8-CRLF2 rearrangement is associated with an intermediate to poor outcome, its role with respect to relapse disposition is not fully clear, as the P2RY8-CRLF2 rearrangement has been reported in some cases to be lost at relapse, particularly when it has been identified initially in a sub-clone only. ${ }^{35-38}$ About one-third of $B C R$ - $A B L 1$-like non-CRLF2 rearranged ALL cases present chromosomal rearrangements that result in constitutive deregulation of a cytokine receptor or the formation of kinase fusion genes: a major subgroup includes $\mathrm{ABL}$-class alterations involving $A B L 1, A B L 2$, CSF1R, LYN, PDGFRA and PDFGRB. A second major group regards rearrangements that activate JAK family kinases, including JAK2, EPOR, TYK2 and IL2RB. A third group constitutes a variety of other kinases or cytokine receptor alterations such as NTRK3, FLT3, FGFR1 and BLNK, and the RAS signaling pathway. ${ }^{11,13,23,29,32-39}$

The limited data available confirm that $B C R-A B L 1$-like ALL is associated with high-risk features also in pediatric patients. A single institution reported that the outcome in $B C R-A B L 1$-like ALL patients, although inferior to that of other patients, was favorable with MRD-driven therapy and with the majority of patients treated in the higher risk arms and $15 \%$ undergoing HSCT. ${ }^{23,24}$ Subsequently, the COG found that, within standard risk ALL patients defined by National Cancer Institute (NCI) criteria, Ph-like ALL patients had a still good, but significantly lower, event-freesurvival and no significant difference in survival when compared to non-Ph-like NCI standard risk ALL. ${ }^{40}$ In keeping with these data, Boer reported an increased cumulative incidence of relapse in $B C R$-ABL1-like ALL compared to non$B C R$-ABL1-like B-other ALL. ${ }^{26}$ Finally, the AIEOP-BFM study group has recently reported the outcome of $\mathrm{ABL}$-class fusion positive BCP-ALL in a retrospective study, which, although limited by its retrospective nature, and especially by a potential selection bias towards cases with a poor treatment response, indicates that these patients have an overall poor prognosis. ${ }^{41}$

The role of CRLF2 abnormalities on BCR-ABL1-like ALL outcome is still controversial. The COG showed that, while high CRLF2-expression predicted a dismal outcome in high-risk patients, the two specific genomic CRLF2-lesions did not confer independent prognostic significance. ${ }^{42}$ Similarly, CRLF2-rearrangements had no independent prognostic value in the Medical Research Council ALL97 trial, ${ }^{43}$ while the AIEOP-BFM study group reported that P2RY8CRLF2 positive patients allocated in the non-HR group had a poorer prognosis. ${ }^{35,36}$ However, it should be remembered that data on CRLF2-rearranged BCP-ALL are not exclusively restricted to cases with $B C R$ - $A B L 1$-like gene expression signature. Outcome data on $B C R$ - $A B L 1$-like ALL are summarized in Table 1. Overall, these data confirm that there is a clinical need for innovative targeted therapies which may be effective in this ALL subtype, as suggested by pre-clinical studies.

In vitro studies have, in fact, demonstrated constitutive activation of kinase signaling networks in subsets of $B C R$ ABL1-like ALL harboring JAK pathway aberrations, ${ }^{42,44,45}$ and in vivo studies have demonstrated anti-leukemic activity of the type I JAK2 inhibitor ruxolitinib and of the dual $\mathrm{PI} \mathrm{K} / \mathrm{mTOR}$ inhibitor gedatolisib given as a monotherapy in patient-derived xenograft models of JAK pathwaymutant $B C R$ - $A B L 1$-like ALL. ${ }^{44,46-50}$ Other studies have reported superior anti-leukemic efficacy with the type II JAK inhibitor CHZ868, which synergizes with dexamethasone to induce apoptosis, suggesting that type II JAK2 inhibition may be more effective to target CRLF2-rearranged BCPALL. This may be because type II inhibitors stabilize JAK2 in the inactive conformation, and overcome the JAK2 hyperphosphorylation observed with type I JAK inhibitors which target the ATP binding pocket and stabilize JAK2 in the active conformation. ${ }^{51}$ Likewise, pre-clinical experimental studies have shown that cell lines and human cells expressing ABL-class fusions, as well as patient-derived xenograft models, have marked sensitivity to the TKI such as imatinib and dasatinib, similarly to $B C R-A B L 1$ cells. $^{52}$

Clinical studies are still very limited. A COG phase I trial (ADVL1011; clinicaltrials.gov identifier: 01164163) demonstrated the safety of JAK2 inhibitor ruxolitinib, given as monotherapy in children with relapsed or refractory cancers ${ }^{53}$ while anecdotal reports have provided evidence of efficacy of TKI (imatinib and dasatinib) to induce remission and clear MRD in patients with ABL-class fusions with poor response to previous chemotherapy. ${ }^{5456}$

Optimal clinical management of pediatric $B C R$ - $A B L 1$-like ALL, thus, remains to be defined. The heterogeneous genomic landscape and the diverse array of targetable kinase-activating lesions of $B C R-A B L 1-$ like ALL require precise diagnostic strategies. Initially, the DCOG group used a validated Affymetrix gene expression array which included 110 probe sets, while the COG and SJCRH used an Affymetrix gene expression array with 255 probe sets to screen patients for $B C R-A B L 1$-like ALL signature. Subsequently, COG first utilized a quantitative reverse transcriptase polymerase chain reaction (RT-PCR)-based low density array (LDA) platform to identify patients with $B C R$ - $A B L 1$-like ALL enrolled in their ALL COG front-line AALL1131 trial. As a second step, a series of multiplex RTPCR assays, fluorescence in situ hybridization (FISH), and DNA sequencing to identify the underlying genomic aberration were applied. ${ }^{57,58}$ The COG is now using Archer targeted RNA sequencing instead of multiplex RT-PCR assays. Alternatively, combined FISH or targeted RNA-next generation sequencing (NGS) strategies with probes capturing the recurrently fused genes can be successfully applied. ${ }^{59}$ In the future, NGS-based whole transcriptome sequencing should allow the detection of all relevant gene fusions and mutations in one step, as recently demonstrated by $\mathrm{Gu}$ et al. ${ }^{60}$ and Li et al. ${ }^{61}$ This approach will facilitate the timed diagnosis and the early implementation of specific treatments. Of note, despite the large number of individual kinase alterations identified, the majority converge on a limited number of pathways that can be targeted.

The best therapeutic strategy for this subgroup of patients remains a matter of investigation. Several ongoing studies are assessing the role of the addition of TKI or ruxolitinib on top of chemotherapy in pediatric BCP-ALL harboring ABL-class fusions or CRLF2/JAK pathway alterations. In the current COG AALL1131 and AALL1521 (clinicaltrials.gov identifier: 02883049 and 02723994, respectively) and SJCRH Total Therapy XVII trials (clinicaltrials.gov identi- 
Table 1. Outcome of $B C R-A B L 1$-like acute lymphoblastic leukemia among different study groups.

\begin{tabular}{|c|c|c|c|}
\hline Study group & Protocol & $\begin{array}{l}\text { N. BCR-ABL1(Ph) - } \\
\text { like ALL patients/total } \\
\text { BCP-ALL }\end{array}$ & Outcome (CIR, EFS, OS) \\
\hline Roberts et al. ${ }^{23}$ & $\begin{array}{l}\text { Total therapy XV, Total therapy XVI, } \\
\text { P9906 AALL0232, E2993, C19802, } \\
\text { C10102 and C10403 }\end{array}$ & $264 / 1725$ & $\begin{array}{l}5 \text {-years pEFS } 58.2 \pm 5.3 \%, 41.0 \pm 7.4 \% \text {, and } 24.1 \pm 10.5 \% \text { for children } \\
\text { with high-risk ALL, adolescents, and young adults; } \\
5 \text {-years pOS } 72.8 \pm 4.8 \%, 65.8 \pm 7.1 \% \text {, and } 25.8 \pm 9.9 \% \text { for children } \\
\text { with high-risk ALL, adolescents, and young adults. Across all } \\
\text { age groups OS rates were inferior to those among patients } \\
\text { with non-Ph-like ALL ( } P<0.001 \text { for both comparisons) }\end{array}$ \\
\hline
\end{tabular}

\begin{tabular}{|c|c|c|c|}
\hline Roberts et al. ${ }^{24}$ & Total therapy XV & $40 / 344$ & $\begin{array}{l}5 \text {-years pEFS } 90.0 \% \pm 4.7 \% \text { vs. } 88.4 \% \pm 0.9 \%, P=0.41 \text { in BCR- } \\
\text { ABL1-like ALL vs. non-BCR-ABL1-like ALL; } 5 \text {-years pOS } \\
92.5 \% \pm 4.2 \% \text { vs. } 95.1 \% \pm 1.3 \%, P=0.41 \text { in BCR-ABL1-like ALL vs. } \\
\text { non-BCR-ABL1-like ALL }\end{array}$ \\
\hline Roberts et al. ${ }^{40}$ & COG AALL0331 & $\begin{array}{c}\text { 206/1023 } \\
\text { Standard-Risk ALL }\end{array}$ & $\begin{array}{l}\text { 7-years pEFS } 82.4 \pm 3.6 \% \text { vs. } 90.7 \pm 1.0 \%, P=0.0022 \text {, Ph-like ALL } \\
\text { vs. non-Ph-like ALL; } 7 \text {-years pOS } 93.2 \pm 2.4 \% \text { vs. } 95.8 \pm 0.7 \% \text {, } \\
P=0.14 \text {, Ph-like ALL vs. non-Ph-like ALL }\end{array}$ \\
\hline Boer et al. ${ }^{26}$ & $\begin{array}{l}\text { DCOG ALL-8, ALL-9, ALL10 } \\
\text { COALL 06-97 and COALL 07-03 }\end{array}$ & $77 / 574$ & $\begin{array}{l}\text { 8-years pCIR } 35 \% \text { vs. 17\%, } P=0.07, \text { BCR-ABL1-like ALL vs. non } \\
\text { BCR-ABL1-like B-other ALL }\end{array}$ \\
\hline Cario et al. ${ }^{41}$ & $\begin{array}{l}\text { AIEOP BFM ALL } 2000 \text { and } \\
\text { AIEOP BFM ALL } 2009\end{array}$ & $\begin{array}{l}46 \text { ABL-class fusion } \\
\text { positive ALL }\end{array}$ & $\begin{array}{l}5 \text {-years pEFS was } 49.1 \pm 8.9 \%, 5 \text {-years pOS } 69.6 \pm 7.8 \% \text { and } 5 \text {-years } \\
\text { CIR was } 25.6 \pm 8.2 \%\end{array}$ \\
\hline
\end{tabular}

ALL: acute lymphoblastic leukemia; BCP-ALL: B-cell precursor acute lymphoblastic leukemia; CIR: cumulative incidence of relapse; EFS: event-free survival; OS: overall survival.

fier: 03117751), ALL patients with NCI high-risk characteristics or poor early MRD response are screened for ABLclass fusions and JAK pathway mutations. In patients positive for these alterations, dasatinib and ruxolitinib, respectively, are given in combination with conventional frontline chemotherapy from the consolidation phase until the end of maintenance therapy. ${ }^{57,62}$ Patients with NCI standard risk characteristics and early good MRD response are not included because available data on their outcome are very limited. ${ }^{48,52}$ Other phase I/II trials conducted at the MD Anderson Cancer Center (clinicaltrials.gov identifier: 02420717) are testing dasatinib or low doses of ruxolitinib in combination with hyper-CVAD (cyclophosphamide, vincristine, doxorubicin, dexamethasone) in adolescents and adults with relapsed/refractory ALL and ABL-class fusions or CRLF2/JAK mutations, respectively; interim data analysis demonstrates the safety of these combinations with limited efficacy. ${ }^{63}$ A recent phase I trial (clinicaltrials.gov identifier: 03571321) at the University of Chicago and other institutions is studying ruxolitinib in combination with the pediatric-inspired CALBG 10403 chemotherapy regimen in adolescents with newly diagnosed Ph-like ALL harboring CRLF2/JAK alterations, with a planned phase II expansion study if safety is demonstrated. ${ }^{64,65}$

In Europe, the AIEOP-BFM ALL and ALLTogether study groups are also investigating the addition of innovative or targeted therapy on top of chemotherapy in BCR-ABL1-like ALL. In the AIEOP-BFM ALL 2017 trial (clinicaltrials.gov identifier: 03643276), patients are screened at diagnosis for IKZF1 deletions, which are frequently found in BCR-ABL1like ALL, and for additional deletions of genes relevant for B-cell development. Those cases defined as IKZF1 plus positive $^{66}$ with any MRD positivity after induction treatment are randomized to receive the proteasome inhibitor bortezomib in addition to chemotherapy during consolidation and to receive the bispecific $\mathrm{T}$-cell engager (BiTE) antibody blinatumomab during post-consolidation treatment.
Especially the approach to apply immunotherapy instead of extremely intensive high-risk blocks may be of advantage for ABL-class-fusion positive cases, bearing in mind the high rate of severe treatment-related complications in $\mathrm{Ph}^{+}$ ALL patients treated with high-risk chemotherapy plus TKI. In the ALLTogether study, patients are screened for ABL-class fusions at diagnosis and those positive receive TKI on top of chemotherapy from day 15 of induction onward. In both AIEOP-BFM and ALLTogether studies, these patients have an indication for HSCT in case of poor MRD response. Likewise, the French CALL-F01 protocol (clinicaltrials.gov identifier: 02716233) has been amended in 2018 to bring to RNA sequencing all B-other ALL in case of induction failure or end of induction MRD above or equal to $10^{-3}$ : these patients are to receive imatinib on top of chemotherapy in the high-risk group. Then, according to subsequent MRD and effective exposure to imatinib, they either continue TKI plus chemotherapy or go to HSCT. A similar approach in the early introduction of a TKI in addition to chemotherapy in ABL-class positive BCP-ALL is planned within the EsPhALL2017/COGAALL1631 protocol (clinicaltrials.gov identifier: 03007147), the first intercontinental collaborative trial for the treatment of pediatric $\mathrm{Ph}^{+} \mathrm{ALL}$ involving COG and EsPhALL study groups. In this trial, an amendment is ongoing to extend the eligibility to patients with ABL-class fusion positive BCP-ALL and, thus, treat them with imatinib given early after diagnosis and continuously on top of high-risk chemotherapy.

Actually, in pediatric patients there is no clear evidence for superiority of a specific type of TKI. In the COG AALL0622 study, dasatinib $\left(60 \mathrm{mg} / \mathrm{m}^{2}\right)$ was substituted for imatinib $\left(340 \mathrm{mg} / \mathrm{m}^{2}\right.$ ) on top of the same chemotherapy backbone of the AALL0031 study with no benefit. The same dose of dasatinib was used also in a joint COG/EsPhALL study (BMS CA180372) on top of the EsPhALL therapeutic strategy with preliminary results which appear similar to the contemporary EsPhALL study 
which used imatinib $\left(300 \mathrm{mg} / \mathrm{m}^{2}\right)$. A very recent study, where dasatinib was used at a higher dose $\left(80 \mathrm{mg} / \mathrm{m}^{2}\right)$ and randomized versus imatinib $\left(300 \mathrm{mg} / \mathrm{m}^{2}\right)$, showed a superiority of dasatinib; however, follow up of this study was relatively short, and results in the cohort treated with imatinib were inferior to those obtained by the EsPhALL and COG groups with the use of imatinib, thus, challenging the evidence of superiority itself. Other TKI such as nilotinib, bosutinib and ponatinib are still being investigated as phase I and II trials in pediatric cancers. At this moment, the choice of both imatinib or dasatinib appears to be reasonable as TKI in frontline ALL protocols for children and adolescents. $7,910,67,68$

In summary, there are still some challenges to implanting targeted therapy into frontline ALL treatment. There is a need for an early identification of BCP-ALL harboring ABL-class and JAK-pathway alterations to allow prompt intervention with targeted therapy to reduce intensity of chemotherapy, and refine HSCT indications, as already shown for $\mathrm{Ph}^{+}$ALL. ${ }^{5-10}$ Diagnostic technologies such as RNA sequencing and similar strategies should be implemented in a timely fashion for all "B-other ALL".
Although ABL-class and JAK-pathway alterations account for most $B C R$ - $A B L 1$-like ALL cases, there are also several alterations involving kinases that are not inhibited by either TKI or JAK inhibitors. Future studies are required to assess the potential of targeted inhibitors of these kinases in model systems and human leukemic cells. In the meantime, for this subgroup of $B C R$ - $A B L 1$-like cases without known targetable lesions, the optimal treatment should be based on MRD response, and might include innovative therapies such as immunotherapy. Moreover, all ALL patients treated with targeted approaches should be registered and closely followed up on the molecular level as recently discussed by Elitzur and Izraeli in order to understand response and resistance to targeted treatment. ${ }^{69}$ Due to the rarity of these clinical entities, collaborative international efforts are strongly needed to conduct successful studies.

\section{Acknowledgments}

The authors would like to thank AIRC 2017 20564: CRUK/AIRC/FC AECC 22791 and AIRC Molecular Clinical Oncology 5 per mille 21147.

\section{References}

1. Hunger SP, Mullighan CG. Redefining ALL classification: toward detecting high-risk ALL and implementing precision medicine. Blood. 2015;125(26):3977-3987.

2. Bernt KM, Hunger SP. Current concepts in pediatric Philadelphia chromosome-positive acute lymphoblastic leukemia. Front Oncol. 2014:4:54.

3. Fielding AK. Treatment of Philadelphia chromosome-positive acute lymphoblastic leukemia in adults: a broader range of options, improved outcomes, and more therapeutic dilemmas. Am Soc Clin Oncol Educ Book. 2015;2e352-359.

4. Aricò M, Schrappe M, Hunger SP, et al. Clinical outcome of children with newly diagnosed Philadelphia chromosome-positive acute lymphoblastic leukemia treated between 1995 and 2005. J Clin Oncol. 2010;28(31):4755-4761.

5. Biondi A, Schrappe M, De Lorenzo P, et al. Imatinib after induction for treatment of children and adolescents with Philadelphiachromosome positive acute lymphoblastic leukaemia (EsPhALL): a randomised, openlabel, intergroup study. Lancet Oncol. 2012;13(9):936-945.

6. Biondi A, Cario G, De Lorenzo P, et al. Longterm follow up of pediatric Philadelphia positive acute lymphoblastic leukemia treated with the EsPhALL2004 study: high white blood cell count at diagnosis is the strongest prognostic factor. Haematologica. 2019;104 (1):13-16.

7 Biondi A, Gandemer V, De Lorenzo P, et al. Imatinib treatment of paediatric Philadelphia chromosome-positive acute lymphoblastic leukaemia (EsPhALL2010): a prospective, intergroup, open-label, singlearm clinical trial. Lancet Haematol. 2018:5(12):641-652.

8 Schultz KR, Bowman WP, Aledo A, et al. Improved early event-free survival with imatinib in Philadelphia chromosome-posi- tive acute lymphoblastic leukemia: a children's oncology group study. J Clin Oncol. 2009;27(31):5175-5181

9 Schultz KR, Carroll A, Heerema NA, et al. Long-term follow-up of imatinib in pediatric Philadelphia chromosome-positive acute lymphoblastic leukemia: Children's Oncology Group Study AALL0031. Leukemia. 2014;28(7):1467-1471.

10 Slayton WB, Schultz KR, Kairalla JA, et al. Dasatinib plus intensive chemotherapy in children, adolescents, and young adults with philadelphia chromosome-positive acute lymphoblastic leukemia: results of Children's Oncology Group Trial AALL0622. J Clin Oncol. 2018;36(22):23062314.

11. Mullighan CG, Su X, Zhang J, et al; Children's Oncology Group. Deletion of IKZF1 and prognosis in acute lymphoblastic leukemia. N Engl J Med. 2009;360(5):470480.

12. Boer JM, Marchante JR, Evans WE, et al. BCR-ABL1-like cases in pediatric acute lymphoblastic leukemia: a comparison between DCOG/Erasmus MC and COG/St. Jude signatures. Haematologica. 2015;100(9):e354357.

13. Den Boer ML, van Slegtenhorst M, De Menezes RX, et al. A subtype of childhood acute lymphoblastic leukaemia with poor treatment outcome: a genome-wide classification study. Lancet Oncol. 2009;10(2):125134.

14. Arber DA, Orazi A, Hasseriian R, et al. The 2016 revision to the World Health Organization classification of myeloid neoplasms and acute leukemia. Blood. 2016;127(20):2391-2405.

15. Harvey RC, Mullighan CG, Chen IM, et al. Rearrangement of CRLF2 is associated with mutation of JAK kinases, alteration of IKZF1, Hispanic/Latino ethnicity, and a poor outcome in pediatric B-progenitor acute lymphoblastic leukemia. Blood. 2010;115(26):5312-5321.

16. Russell LJ, Capasso M, Vater I, et al.
Deregulated expression of cytokine receptor gene, CRLF2, is involved in lymphoid transformation in B-cell precursor acute lymphoblastic leukemia. Blood. 2009;114(13): 2688-2698.

17. Herold T, Schneider S, Metzeler K, et al. Adults with Philadelphia chromosome-like acute lymphoblastic leukemia frequently have IGH-CRLF2 and JAK2 mutations, persistence of minimal residual disease and poor prognosis. Haematologica. 2017; 102(1):130-138

18. Boer JM, Koenders JE, van der Holt B, et al. Expression profiling of adult acute lymphoblastic leukemia identifies a BCR-ABL1like subgroup characterized by high nonresponse and relapse rates. Haematologica. 2015;100(7):261-264

19. Roberts KG, Mullighan CG. Genomics in acute lymphoblastic leukaemia: insights and treatment implications. Nat Rev Clin Oncol. 2015;12(6):344-357.

20. Harvey RC, Mullighan CG, Wang X, et al. Identification of novel cluster groups in pediatric high-risk B-precursor acute lymphoblastic leukemia with gene expression profiling: correlation with genome-wide DNA copy number alterations, clinical characteristics, and outcome. Blood. 2010;116(23):4874-4884.

21. Loh ML, Zhang J, Harvey RC, et al. Tyrosine kinome sequencing of pediatric acute lymphoblastic leukemia: a report from the Children's Oncology Group TARGET Project. Blood. 2013;121(3):485-488.

22. van $\operatorname{der}$ Veer A, Waanders E, Pieters $R$, et al. Independent prognostic value of BCR-ABL1like signature and IKZF1 deletion, but not high CRLF2 expression, in children with Bcell precursor ALL. Blood. 2013;122(15): 2622-2629.

23. Roberts KG, Li Y, Payne-Turner D, et al. Targetable kinase-activating lesions in $\mathrm{Ph}$ like acute lymphoblastic leukemia. N Engl J Med. 2014;371(11):1005-1015.

24. Roberts KG, Pei D, Campana D, et al. Outcomes of children with BCR-ABL1-like 
acute lymphoblastic leukemia treated with risk-directed therapy based on the levels of minimal residual disease. J Clin Oncol. 2014;32(27):3012-3020.

25. Imamura $T$, Kiyokawa N, Kato M, et al. Characterization of pediatric Philadelphia negative B-cell precursor acute lymphoblastic leukemia with kinase fusions in Japan. Blood Cancer J. 2016;6:e419.

26. Boer JM, Steeghs EM, Marchante JR, et al. Tyrosine kinase fusion genes in pediatric BCRABL1-like acute lymphoblastic leukemia. Oncotarget. 2017;8(3):4618-4628.

27. Herold T, Schneider S, Metzeler KH, et al. Adults with Philadelphia chromosome-like acute lymphoblastic leukemia frequently have IGHCRLF2 and JAK2 mutations, persistence of minimal residual disease and poor prognosis. Haematologica. 2017;102 (1):130-138.

28. Jain N, Roberts KG, Jabbour E, et al. Ph-like acute lymphoblastic leukemia: a high-risk subtype in adults. Blood. 2017;129(5):572581.

29. Reshmi SC, Harvey RC, Roberts KG, et al. Targetable kinase gene fusions in high-risk B-ALL: a study from the Children's Oncology Group. Blood. 2017;129(25): 3352-3361.

30. Tran TH, Loh ML. Ph-like acute lymphoblastic leukemia. Hematology Am Soc Hematol Educ Program. 2016;2016(1):561-566.

31. Roberts KG, Gu Z, Payne-Turner D, et al. High frequency and poor outcome of philadelphia chromosome-like acute lymphoblastic leukemia in adults. J Clin Oncol. 2017;35(4):394-401.

32. Roberts KG, Morin RD, Zhang J, et al. Genetic alterations activating kinase and cytokine receptor signaling in high-risk acute lymphoblastic leukemia. Cancer Cell. 2012;22(2):153-166.

33. Mullighan CG, Collins-Underwood JR, Phillips LA, et al. Rearrangement of CRLF2 in B-progenitor- and Down syndrome-associated acute lymphoblastic leukemia. Nat Genet. 2009;41(11):1243-1246.

34. Yoda A, Yoda Y, Chiaretti S, et al. Functional screening identifies CRLF2 in precursor Bcell acute lymphoblastic leukemia. Proc Natl Acad Sci USA. 2010;107(1):252-257.

35. Cario G, Zimmermann M, Romey R, et al. Presence of the P2RY8-CRLF2 rearrangement is associated with a poor prognosis in non-high-risk precursor B-cell acute lymphoblastic leukemia in children treated according to the ALL-BFM 2000 protocol. Blood. 2010;115(26):5393-5397.

36. Palmi C, Vendramini E, Silvestri $\mathrm{D}$, et al. Poor prognosis for P2RY8-CRLF2 fusion but not for CRLF2 over-expression in children with intermediate risk B-cell precursor acute lymphoblastic leukemia. Leukemia. 2012;26(10):2245-2253

37. Morak M, Attarbaschi A, Fischer S, et al. Small sizes and indolent evolutionary dynamics challenge the potential role of P2RY8-CRLF2-harboring clones as main relapse-driving force in childhood ALL. Blood. 2012:120(26):5134-5142.

38. Attarbaschi A, Morak M, Cario G, et al. Treatment outcome of CRLF2-rearranged childhood acute lymphoblastic leukaemia: a comparative analysis of the AIEOP-BFM and UK NCRI-CCLG study groups. Br J Haematol. 2012:158(6):772-777.

39. Roberts KG, Yang Y, Turner DP, et al. Oncogenic role and therapeutic targeting of
ABL-class and JAK-STAT activating kinase alterations in Ph-like ALL. Blood Adv. 2017;1(20):1657-1671.

40. Roberts KG, Reshmi SC, Harvey RC, et al. Genomic and outcome analyses of Ph-like ALL in NCI standard-risk patients: a report from the Children's Oncology Group. Blood. 2018;132(8):815-824

41. Cario G, Leoni V, Conter V, et al. Relapses and treatment-related events contributed equally to poor prognosis in children with ABL-class fusion positive B-cell acute lymphoblastic leukemia treated according to AIEOP-BFM protocols. Haematologica. 2019 Oct 10. [Epub ahead of print].

42. Chen IM, Harvey RC, Mullighan CG, et al. Outcome modeling with CRLF2, IKZF1, JAK, and minimal residual disease in pediatric acute lymphoblastic leukemia: a Children's Oncology Group study. Blood. 2012;119(15):3512-3522.

43. Ensor HM, Schwab C, Russell LJ, et al Demographic, clinical, and outcome features of children with acute lymphoblastic leukemia and CRLF2 deregulation: results from the MRC ALL97 clinical trial. Blood. 2011;117(7):2129-2136.

44. Maude SL, Tasian SK, Vincent $T$, et al. Targeting JAK1/2 and mTOR in murine xenograft models of $\mathrm{Ph}$-like acute lymphoblastic leukemia. Blood. 2012;120(17): 3510-3518.

45. Tasian SK, Doral MY, Borowitz MJ, et al Aberrant STAT5 and PI3K/mTOR pathway signaling occurs in human CRLF2rearranged B-precursor acute lymphoblastic leukemia. Blood. 2012;120(4):833-842.

46. Suryani S, Bracken LS, Harvey RC, et al. Evaluation of the in vitro and in vivo efficacy of the JAK inhibitor AZD1480 against JAKmutated acute lymphoblastic leukemia. Mol Cancer Ther. 2015;14(2):364-374

47. Tasian SK, Teachey DT, Li Y, et al. Potent efficacy of combined PIBK/mTOR and JAK or ABL inhibition in murine xenograft models of Ph-like acute lymphoblastic leukemia. Blood. 2017;129(2):177-187.

48. van Bodegom D, Zhong J, Kopp N, et al Differences in signaling through the B-cell leukemia oncoprotein CRLF2 in response to TSLP and through mutant JAK2. Blood. 2012:120(14):2853-2863.

49. Weigert O, Lane AA, Bird L, et al. Genetic resistance to JAK2 enzymatic inhibitors is overcome by HSP90 inhibition. J Exp Med. 2012;209(2):259-273

50. Wu SC, Li LS, Kopp N, et al. Activity of the type II JAK2 inhibitor CHZ868 in B cell acute lymphoblastic leukemia. Cancer Cell. 2015; 28(1):29-41.

51. Koppikar P1, Bhagwat N, Kilpivaara O, et al Heterodimeric JAK-STAT activation as a mechanism of persistence to JAK2 inhibitor therapy. Nature. 2012;489(7414):155-159.

52. Roberts KG, Morin RD, Zhang J, et al Genetic alterations activating kinase and cytokine receptor signaling in high-risk acute lymphoblastic leukemia. Cancer Cell. 2012;22(2):153-166

53. Loh ML, Tasian SK, Rabin KR, et al. A phase 1 dosing study of ruxolitinib in children with relapsed or refractory solid tumors, leukemias, or myeloproliferative neoplasms: A Children's Oncology Group phase 1 consortium study (ADVL1011). Pediatr Blood Cancer. 2015:62(10):1717-1724.

54. Lengline E, Beldjord $\mathrm{K}$, Dombret $\mathrm{H}$, et al. Successful tyrosine kinase inhibitor therapy in a refractory B-cell precursor acute lymphoblastic leukemia with EBF1PDGFRB fusion. Haematologica. 2013;98(11):146148.

55. Weston BW, Hayden MA, Roberts KG, et al Tyrosine kinase inhibitor therapy induces remission in a patient with refractory EBF1PDGFRB-positive acute lymphoblastic leukemia. J Clin Oncol. 2013;31 (25):413416.

56. Tanasi I, Ba I, Sirvent N, et al. Efficacy of tyrosine kinase Inhibitors in Ph-like acute lymphoblastic leukemia harboring $\mathrm{ABL}$ class rearrangements. Blood. 2019;134(16): 1351-1355.

57. Tasian SK, Loh ML, Hunger SP. Philadelphia chromosome-like acute lymphoblastic leukemia. Blood. 2017;130(19): 2064-2072.

58. Schwab C, Ryan SL, Chilton L, et al. EBF1PDGFRB fusion in pediatric $\mathrm{B}$-cell precursor acute lymphoblastic leukemia (BCP-ALL) genetic profile and clinical implications. Blood. 2016;127(18):2214-2218.

59. Grioni, A, Fazio G, Rigamonti S, et al. A simple RNA target capture NGS strategy for fusion genes assessment in the diagnostics of pediatric B-cell acute lymphoblastic leukemia. HemaSphere. 2019;3(3):e250.

60. Gu Z, Churchman ML, Roberts KG, et al. PAX5-driven subtypes of B-progenitor acute lymphoblastic leukemia. Nat Genet. 2019;51(2):296-307

61. Li JF, Dai YT, Lilljebjörn $\mathrm{H}$, et al Transcriptional landscape of B cell precursor acute lymphoblastic leukemia based on an international study of 1,223 cases. Proc Nat Acad Sci U S A. 2018:115(50):11711-11720.

62. Maese L, Tasian SK, Raetz EA. How is the $\mathrm{Ph}$-like signature being incorporated into therapy? Best Pract Res Clin Haematol. 2017;30(3):222-228

63. Jain N, Jabbour EJ, McKay PZ, et al. Ruxolitinib or dasatinib in combination with chemotherapy for patients with relapsed/refractory Philadelphia (Ph)-like acute lymphoblastic leukemia: a phase I-II trial. Blood. 2017;130(suppl 1):1322

64. Curran E, Stock W. How I treat acute lymphoblastic leukemia in older adolescents and young adults. Blood. 2015;125(24):37023710.

65. Stock W, Luger SM, Advani AS, et al. A pediatric regimen for older adolescents and young adults with acute lymphoblastic leukemia: results of CALGB 10403. Blood. 2019;133(14):1548-1559.

66. Stanulla M, Dagdan E, Zaliova $M$, et al IKZF1plus defines a new minimal residual disease-dependent very-poor prognostic profile in pediatric B-cell precursor acute lymphoblastic leukemia. J Clin Oncol 2018;36(12):1240-1249.

67. Hunger SP, Saha V, Devidas M, et al. CA180372: An international collaborative phase 2 trial of dasatinib and chemotherapy in pediatric patients with newly diagnosed Philadelphia chromosome positive acute lymphoblastic leukemia ( $\mathrm{Ph}+\mathrm{ALL})$ Blood. 2017;130 (Supplement 1):98.

68. Shen S, Chen X, Cai J, et al. Effect of dasatinib vs imatinib in the treatment of pediatric Philadelphia chromosome-positive acute lymphoblastic leukemia: a randomized clinical trial. JAMA Oncol. 2020 Jan 16 [Epub ahead of print].

69. Elitzur S, Izraeli S. Genomic precision medicine: on the TRK. Blood. 2018;132(8):773774. 